and the heart's apex beat in the natural position. His pulse was regular and of good volume, but very slow, beating only 36 to the minute. On listening over the heart's apex, a very remarkable complex bruit was heard. There was first a loud prolonged systolic murmur, and then immediately after, two short sounds; so that between each beat of the heart we heard three distinct murmurs : a long and loud murmur (systolic), a short and softer murmur (post-systolic), and another short and soft murmur (presystolic). The unusual slowness of the heart's nction enabled us to separate this complex sound very easily and distinctly into its component elements. Systolic and diastolic aortic murmurs were also audible at the base.

A few days after the appearance of this patient at King's College Hospital his wife came to say that he had died rather suddenly the night before. As I was desirous of satisfying myself-(1) as to the cause of the epigastric pulsation and pain (this being the man's chief trouble); (2) as to the precise condition which gave rise to the curious murmur we heard ; and (3) as to its connexion with the unusual slowness of pulse, I asked and obtained permission to make a post-mortem examination.

On opening the chest we found the pericardium uniformly adherent to every part of the heart's surface. The heart was flabby, its cavities considerably dilated, and their walls thinned, that of the right ventricle being very thin. The right side of the heart was distended with clot, and so was the left auricle, which was enormously dilated to three or four times its natural size. The mitral orifice was considerably diminished in circumference, the segments of the mitral valve were thickened, somewhat puckered at their free edges, and adherent to one another by their adjacent margins. The orifice was nearly circular in form, and about three-fourths of an inch in diameter. The aortic valves were also thickened, and to some extent disabled. A slight festooned fringe of fibrin was observed just beneath the free margin of each valve, and two of the valves were adherent by their contiguous sides.

We can now see how the physical signs observed during life were produced. The first loud and long bruit heard at the apex was clearly a regurgitant one, accompanying the systole of the ventricle. The next short sound was postsystolic, and caused by the commencement of the flow of blood from the auricle into the ventricle through the contracted and somewhat rigid mitral valve (or it may have been produced, as Dr. G. Johnson suggests, who examined the case with me, by aortic regurgitation, and in that case was diastolic aortic). The third sound was pre-systolic, and coincided with the contraction of the greatly dilated auricle, which slowly and with difficulty gathered up force enough to complete its systole. We can also understand how the retardation of the pulse was brought about. The ventricle had to wait, as it were, on the auricle; and the auricle, owing to its great distension, and the thinness of its walls, could only empty itself slowly and with great difficulty. In this way the pulse was delayed, and death was probably caused by the inability, at length, of the left auricle to empty itself.

The epigastric pulsation, so much complained of during the life of the patient, seemed to be due to the uniform adhesion of the pericardium, by means of which the diaphragm was so stuck to the surface of the heart that at each pulsation it moved with it, and its movements were conveyed by a flatulently-distended stomach to the surface.

st. James's-street, S.W.

\section{ON TWO CASES OF CLOSURE OF THE VAGINA.}

By S. CHARLES SMITH, M.R.C.S., L.R.C.P., SURGEON TO THE HALIMAX INTIRMAJY.

Closure of the vagina, more or less complete, is a condition not very uncommonly met with, but in a great majority of instances it is merely the result of some malformation of the bymen. The two following cases, however, are examples of much rarer forms of irregular development of the genital organs : in one, the vagina was to all appearance completely closed about an inch above its orifice, but was in reality carried up to the uterus by a narrow, fistulous track, difficult both to discover and to dilate; in the other, the vagina was altogether occluded at its upper end where the uterus should be inserted into it, and this latter organ was absent.

CASE 1.-E. H-, aged twenty-four, married, was admitted to the Halifax Infirmary on August 7th, 1872, and gave the following history :-The patient had been married ten months; before this she never suspected that there was anything amiss, but soon afterwards began to suffer from various vague dyspeptic and hysterical ailments. Coitus had never been complete. The catamenia had always been regular, and had continued so after her marriage for about four months, since when there had been no discharge, but each period had been marked by the occurrence of violent pain in the back and belly. There had been no enlargement of the abdomen.

On examination of the genital organs it was found that, although the external parts and nymphro were sufficiently well-developed, the vagina was a mere cul-de-sac, about an inch in length. The finger being introduced into the rectum and a sound into the bladder, it became evident that above this cul-de-sac the vagina was absent, the sensation imparted to the finger making it certain that there was only a very thin layer of tissue interposed between it and the point of the sound; further up, however, the bladder and rectum were separated by a mass occupying the position of the uterus.

The undoubted occurrence of the catamenial discharge made me feel certain, not only that there was a uterus, but that a passage to it must somewhere or other exist. On more minute inspection, it was found that about half an. inch behind the urinary meatus there was a small orifice in the upper wall of the rudimentary vagina; this, however, also at first appeared to be merely a blind pouch, the sound not passing into it more than a quarter of an inch; but by the exercise of considerable patience, I was enabled to introduce a bent probe to the extent of about three inches, passing it up a sort of sinus of which this orifice was the external opening. The great tenuity of the parts made it necessary to use the utmost gentleness in handling the probe, the point of which, however, was felt by the finger in the rectum to have arrived close to the mass already mentioned as occupying the situation of the uterus. From this examination it appeared that in place of the vagina there existed only a fistulous track leading from the uterus to the external parts, and from the absence of all history of violence or injury one was forced to believe that this condition was a congenital defect.

The treatment adopted was dilatation by laminaria tents. At first it was not possible to nake one enter for more tharr half an inch, but when this had become swollen, it was found practicable to introduce a second to its entire length; and after this, dilatation was carried on by the use of $\mathbf{x}$ gradually increasing mass of laminaria, until the fistulous. track, which stood in the place of a vagina, was enlarged to such an extent that a speculum could be passed with ease. This process of expansion, however, was clearly not altogether free from risk; a considerable discharge was set up, and several times such an amount of fever arose, with pain and tenderness of the abdomen, that all active measures had to be desisted from, and recourse be taken to salines, sedatives, and fomentations.

On examination with the speculum, the os uteri was readily seen, not, however, standing upon a neck, but attached all round to the walls of the new vagina; the uterine sound was introduced, and entered to the depth of two inches, and on examination per anum, while it was in position, it was found to have passed to that extent into the uterine substance.

She left the infirmary on Oct. 16th. On Nov. 5th she states that the catamenia have again appeared, having been preceded for a couple of days by considerable pain, which, however, ceased on the establishment of the discharge. Since she has returned to her home she has lost her dyspeptic pains, has gained flesh, and considers herself well.

CASE 2.-M. H-, aged nineteen, was brought to me on Nov. 10th, 1872, when the following notes were taken:-Is a thin, ill-developed-looking, flat-breasted girl; she has never menstruated, nor has she ever felt any of the usual symptoms of commencing menstruation.

On examination, it is found that the ragina is roomy, but very smooth and thin-walled, that its upper extremity does not contain a cervix uteri, and that the finger perceives no 
sensation as of any mass in the position of the uterus. On examination per anum, no uterus can be found, and a sound placed in the bladder is felt distinctly as far up as can be reached, while a second sound passed up to the top of the vagina marks on the finger the place where the uterus ought to be.

In each of these two cases the mere introduction of the finger showed only that the vagina was closed, in the one case near to its external orifice, and in the other at its upper extremity, but in neither did it afford any definite information regarding the state of the parts beyond the obstruction, nor could the fact that the uterus was not felt by the finger so introduced be taken as any sufficient proof of the absence of that organ. By the very simple contrivance, howe ver, of placing the finger in the rectum and a sound in the bladder, an accurate idea was gained of the condition of the structures between them, and thus I was enabled in the one case to determine the existence of a uterus, and by treatment to restore the patient, if not to a normal, at any rate to an apparently normal state, and in the other to make certain that a uterus did not exist, and to assure the patient of the uselessness of continuing the treatment for the relief of her amenorrhoea, with which she had been occupying herself for the last three years.

Ward's End, Halifax.

\section{A COMBINED SPIROMETER, ASPIRATOR,} AND AEROSCOPE.

BY ALEXANDER RATTRAY, M.D. EDIN., R.N., H.M.S. "BRTTANNIA,"

THE Spirometer is one of the best tests of the physical condition of the lungs, both in health and disease. Where active pulmonary or cardiac mischief exists, it must be used with caution; but otherwise its judicious employment is not so dangerous as is sometimes supposed.

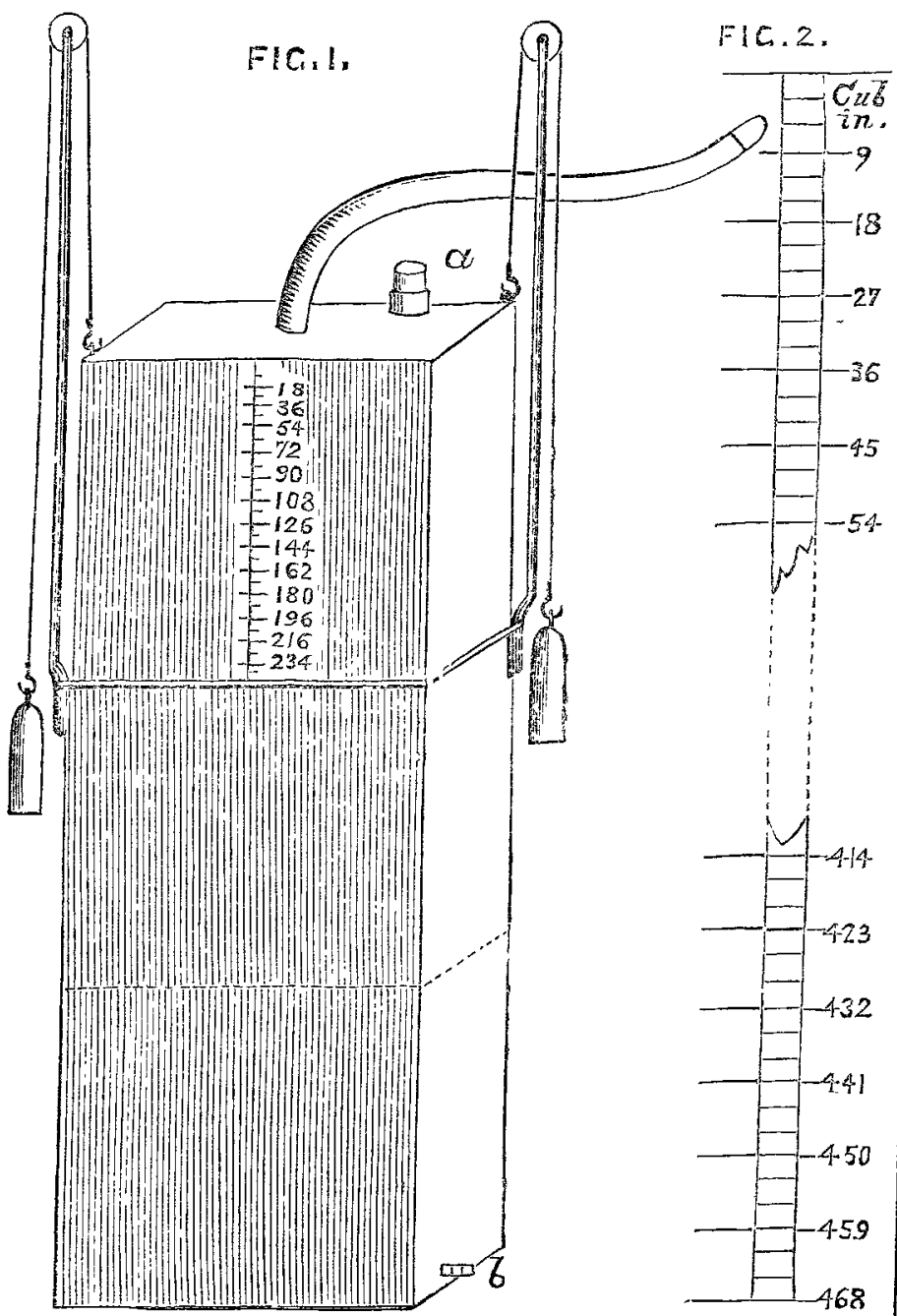

The sketch is that of a spirometer extensively used by me for some years, especially in physiological experiment. Any intelligent workman may make it for ten shillings, or less.
Besides its simplicity and delicacy, its strength, compactness, easy stowage, portability, and fitness for all climates, make it especially adapted for the services. The instrument is a modification of Hutchinson's ; its principle that of the ordinary gasometer. For stability and economy of space, the cylinders are square; the inner of the thinnest-i.e., lightest-sheet zinc, $6 \times 6$ in. wide, 13 in. high, and accurately counterpoised by weights of lead covered by brass or copper, hanging by 24 -inch long silk or catgut cords, over two pulley-tipped $\frac{1}{4}$-inch brass rods, 14 inches long, placed at opposite corners. The breathing tube, 1 inch in diameter, and 28 in. long, with an ebony or ivory mouth-piece, should be attached to the centre of the top of the inner cylinder, either by a simple or screw attachment. A half-inch corkfitted tap (a) gives entrance or exit to air when needed, and a smaller one $(b)$ in the outer cylinder an outlet for the contained water. By making the weights and cords to unhook, and the rods to unship, they may be packed inside for carriage. The index on the inner cylinder (Fig. 2) marks 36 cubic inches of air per inch, and is graduated to indicate a difference of three cubic inches, and even of one. For elegance, the screws, taps, \&c., may be brass; but the above serves every practical purpose. The instrument should not be painted or japanned, as zinc does not corrode, or becomes covered only with a thin coating of carbonate of zinc by the breath, which can be easily removed.

To use it as an Aspirator to pass air or gases through fluids, attach a suitable, finely-pointed glass tube to the mouth-piece, then fill the spirometer, and, by hand or weight pressure, empty it slowly through the fluid. The index shows the exact quantity of air thus used.

For an Aeroscope, to examine floating matter in air, fit the mouth-piece with a suitable nozzle, and either draw the air through this by slowly raising the inner cylinder, or first fill the latter, and then slowly empty it by the nozzle. Dartmouth.

\section{eftledical Sorretites.}

\section{OBSTETRICAL SOCIETY OF LONDON.}

WEDNESDAY, DEC. 4TH, 1872.

\section{Dr. Braxton Hicks, F.R.S., Prestdent, in the Chair.}

The following gentlemen were elected Fellows of the Society :-Edward N. Carless, M.B., Devizes; James Lovegrove, Esq., Sevenoaks; Charles Sangster, Esq.; John Williams, M.D. ; and R. A. H. Wood, Esq., Liverpool.

Dr. WILtshrRe exhibited for Mr. Lawson Tait a case containing various medicated uterine bougies and cloth plugs.

Dr. EDIs read a paper

ON THE SYSTEMATIC EXAMINATION OF THE ABDOMEN, WITH A VIEW TO RECTIFYING MALPOSITIONS OF THE FGTUS DURING IABOUR.

In bringing the subject prominently before the Society, it was not so much with the idea of advancing any novel mode of procedure as of inculcating more earnestly the universal adoption of this simple expedient, which he felt would tend materially to diminish the large mortality annually occurring in Great Britain from accidents of childbirth. It might well be adrocated by our systematic authors and clinical teachers that every student should be taught to consider it his duty to examine carefully the position of the fœtus in utero on first visiting his patient in labour. Dr. Barnes, in his lectures, states : "A head-presentation is the type of natural labour; it follows that to obtain a head-presentation is the great end to be contemplated by art. Yet delivery by the feet is almost invariably practised when turning has to be accomplished. Why is this? The answer is not entirely satisfactory. It rests chiefly on the undoubted fact that in the great majority of instances at the time when a malpresentation comes before us, demanding skilled assistance, turning by the feet is the only mode of turning which is practicable." In transverse presentations, the patient herself of ten notices that she has carried this child differently from the others, and yet the attendant fails to utilise the hint until too late. The process of external version Dr. Edis described as very simple. With the patient on her back, and the knees $\mathrm{CC} 2$ 